\title{
Voting under the Threat of Secession: Accommodation vs. Repression ${ }^{1}$
}

\author{
Vincent Anesi ${ }^{2}$ \\ University of Nottingham \\ Philippe De Donder ${ }^{3}$ \\ Toulouse School of Economics
}

9th May 2012

\footnotetext{
${ }^{1}$ This paper has been presented at seminars and conferences in Barcelona, Iasi, Malaga, Marseille, Rotterdam, Toulouse and Verona. We thank participants and M. Le Breton for their comments and suggestions. This paper has been written in part while the second author was visiting the CES at the University of Munich. He thanks the CES for its very generous hospitality.

${ }^{2}$ School of Economics, Room B18, The Sir Clive Granger Building, University of Nottingham, University Park, Nottingham, NG7 2RD, United Kingdom. Email: vincent.anesi@nottingham.ac.uk.

${ }^{3} 21$ allée de Brienne, 31000 Toulouse. France. Email: dedonder@cict.fr
} 


\begin{abstract}
We build a simple model of secession crises where a majority of voters may wish to accommodate a minority in order to prevent a secession attempt. We first show the existence of a majority voting equilibrium, where the median voter is decisive and most prefers a government's type that is biased in favor of the minority. We propose a measure of the secession risk at equilibrium, which depends upon the comparison of the willingness to secede by the minority and to accommodate by the majority. We show that focusing only on the willingness to secede, as previous literature has done, is misleading when studying the impact on the risk of secession of the size of the minority region, the probability that a secession attempt by the minority is successful, and the cultural heterogeneity in the country.
\end{abstract}

Keywords: Majority voting, secession risk, cultural distinctiveness, conflict, overlapping regional preferences.

JEL Codes: D72, D74 


\section{Introduction}

Country boundaries have been in flux for a long time. For instance, the number of internationally recognized countries has grown from 74 in 1945 to 193 in 2007 (Spolaore, 2008). Some of these new countries have been born following a peaceful separation from larger blocks: this has been the case recently with the breaking-up of the Soviet Union and of Czechoslovakia, or with the separation of Slovenia from Yugoslavia. In many other cases, secession attempts have been less than peaceful, with sometimes bloody secession crises, such as with Bosnia, Chechnya, Croatia, Eritrea, Kosovo, South Sudan or Timor Leste. Other, less recent violent secession episodes include Ireland, Bangladesh, Pakistan and India, etc. There are also many countries where secession, although not (yet) attempted, is at least talked about. Prominent examples include Belgium, Spain, Canada, etc. Gurr (2000) states that, between 1985 and 1999, secessionist movements were present in at least 52 countries.

From this panorama, we gather that there are three main ways a country subject to internal secessionist tensions may respond. One possibility is for the majority ${ }^{1}$ to try to accommodate and placate the minority in order to prevent it from attempting to secede. This is the route taken for now by Spain and Canada with, respectively, Catalonia and Quebec, for instance. If accommodation is not attempted or fails to assuage the disgruntled minority, secession attempts may be either fought by the majority (resulting in a violent secession crisis) or accepted, leading to a peaceful separation. The objective of this paper is to understand what determines which of these three outcomes emerges in countries experiencing secessionist tensions.

The economic literature has focused on the incentives to secede by a minority inside a country - i.e., Alesina and Spolaore (1997), Goyal and Staal (2004), Le Breton and Weber $(2003,2004)$, Haimanko et al. (2005, 2007), and Drèze et al. (2007), to name a few. Many contributions have adopted a cost-benefit approach: factors that make secession more profitable to the minority (self-determination or "government closer to the people," support of neighboring state, ...) should increase the risk of secession, while factors that make secession more costly to the minority (economic losses, security, international hostility, ...) should reduce it.

These contributions (which we dub CCB, for classical cost-benefit approach) abstract from decisions by the majority either to preempt secession by accommodating the minority, or to either fight or accept secession once it is attempted. In order to incorporate those decisions, we build on Alesina and Spolaore (1997). Their model appears to be particularly well suited to our purpose, for it nicely captures the trade-off between the cultural benefits and the economic costs of secession. We adapt this model in order to study how the majority takes these secession incentives

\footnotetext{
${ }^{1}$ From now on, we assume, in line with most of the empirical evidence (see Lustick et al., 2004), that the group tempted by secession forms a minority of the country.
} 
into account when deciding whether to prevent, accept or fight a secession attempt by the minority.

In this paper, citizens belong to one of two regions of different sizes. They differ according to their most-preferred type of a public good associated with the functioning of a country, with individuals' utility decreasing in the distance between most-preferred and majority chosen type of public good. The distributions of mostfavoured types differ from one region to the other, and may be overlapping. By seceding, a region can ensure that the type of the public good better fits its members' tastes: ideological considerations favour secession. On the other hand, economic factors run against secession, because of returns to scale in the provision of the public good provided by the government. The trade-off between these two forces determines both how willing the minority region is to secede, and how willing the majority region is to accommodate the other region to prevent it from seceding. The sequence of decisions (all taken by majority voting) we consider runs as follows. After a national vote on the public good's type is taken, the minority region decides whether to secede or not. The majority region then chooses whether to fight this secession attempt or not. In the latter case, secession occurs peacefully while, in the former case, a costly secession crises occurs, whose outcome is either a successful secession or the maintenance of the unified country. When secession happens, each region forms a new country and decides independently about its public good type. ${ }^{2}$

We first identify the condition under which the majority region fights a secession attempt rather than accepting a peaceful separation. We assume throughout the paper that this condition is satisfied, in order to focus on the choice between accommodation and repression by the majority region. We then show that the agent with the median national location is decisive when voting over the national government's type, but that this individual may favor a government's type that is biased in the direction preferred by the minority. More precisely, accommodation is represented by a threshold of government's type, indicating how much the decisive national voter is ready to depart from the median location in order to prevent the minority from seceding. Similarly, the willingness to secede is given by another threshold, indicating what it the worst type that the minority is ready to accept rather than attempting secession. The comparison between these two thresholds determines both whether accommodation by the majority prevents a secession attempt by the minority, and what policy is implemented when accommodation occurs at equilibrium.

We then study how the equilibrium risk of secession is affected by changes in the

\footnotetext{
${ }^{2}$ The most closely related article is Spolaore (2008): we have in common that we model a two-region setting where the decisions by the minority to secede and by the majority to fight or not secession are driven by the same trade-off between returns to scale and heterogeneity of preferences. However, Spolaore (2008) focuses on the cost of conflict and does not allow the majority to accommodate the minority, but only to fight more or less intensively its secession attempt.
} 
parameters of the model. ${ }^{3}$ The message of the paper is that, by focusing exclusively on the willingness to secede, the CCB approach misses part of the picture (namely, the willingness by the majority to accommodate) and consequently may misidentify how the equilibrium risk of secession changes. We identify three areas where our model generates predictions different from the CCB approach: they concern the impact on the risk of secession of the size of the minority region, the probability that a secession attempt by the minority is successful, and the cultural heterogeneity in the country. The CCB approach predicts that the risk of secession increases with both the size of the minority and the probability that a secession attempt succeeds because they both increase the willingness to secede by the minority. We show that they also increase simultaneously the willingness to accommodate by the majority, resulting in an ambiguous impact on the secession risk (measured as an increasing function of the difference between the willingness to secede and to accommodate). We also show in the final section that the empirical literature seems more in line with our prediction than with the CCB's one. As for the impact of cultural heterogeneity, we highlight the importance of distinguishing inter- from intra-regional heterogeneity. For the former, we show that, although more heterogeneity has an ambiguous impact on the willingness to secede, it nevertheless always increases the secession risk. As for the latter, we obtain the opposite conclusion to the one drawn by the CCB approach: while intra-regional heterogeneity in the main region (resp., the minority region) always increases (resp., decreases) the willingness to secede of the minority, it decreases (resp., increases) the equilibrium secession risk because it increases (resp., decreases) even more the willingness to accommodate of the majority. Unfortunately, it proves difficult to test our predictions empirically, because the empirical literature has failed to distinguish intra- from inter-regional cultural heterogeneity. We then call for more applied research on this topic.

The paper is organized as follows. Section 2 presents the model of voting under the risk of secession, and discusses our key assumptions. Section 3 solves the model while section 4 performs the comparative statics analysis of the equilibrium policy and risk of secession. Finally, section 5 concludes by confronting our results to the existing empirical evidence.

\section{A Simple Model of Secession Crises}

We consider a country populated by a continuum of citizens of total mass one. Citizens belong to one of two regions which we label $A$ and $B$. Let $1-\lambda$ and $\lambda$ stand for the proportion of the country population residing in region $A$ and $B$,

\footnotetext{
${ }^{3}$ To this end, we restrict the (overlapping or not) regional distributions of preferences to be uniform.
} 
respectively. We assume w.l.o.g. that $\lambda<1 / 2$, so that region $B$ is the minority region.

A country needs a government, defined by Alesina and Spolaore (1997, p.1030) as "a bundle of administrative, judicial, economic services, and public policies," and citizens differ in their preferences for the type of government provided. The set of feasible government's types is represented by the interval $[0,1]$, and each citizen's location $t$ on this interval represents her ideal government's type, with her utility decreasing in the distance between ideal and chosen type.

In each region $R \in\{A, B\}$, citizens' types are distributed over the interval $[0,1]$ according to a c.d.f. $F_{a}(t \mid R)$, where $a \in(\underline{a}, \bar{a}) \subseteq \overline{\mathbb{R}}_{++}$is a parameter measuring cultural distinctiveness between regions. The distribution of ideal policies in the country is then given by

$$
F_{a, \lambda}(t) \equiv(1-\lambda) F_{a}(t \mid A)+\lambda F_{a}(t \mid B) .
$$

Throughout the paper, we assume that:

(i) $F_{a}(t \mid A) \geq F_{a}(t \mid B)$, for all $t \in[0,1]$;

(ii) (Regional and national) median types are unique: there exist $t^{A}, t^{B}$, and $t^{m}$ in $[0,1]$ such that

$$
F_{a}^{-1}(\{1 / 2\} \mid R)=\left\{t^{R}\right\}, \forall R \in\{A, B\}, \text { and } F_{a, \lambda}^{-1}(\{1 / 2\})=\left\{t^{m}\right\} .
$$

Furthermore, they satisfy $t^{A}<t^{m}<t^{B}$ and $2 t^{m} \leq t^{A}+t^{B}$.

(iii) For all $t \in[0,1], F_{a}(t \mid A)$ [resp. $\left.F_{a}(t \mid B)\right]$ is an increasing [resp. decreasing] nonconstant function of $a$;

(iv) $\lim _{a \rightarrow \bar{a}} F_{a}(0 \mid A)=1-\lim _{a \rightarrow \bar{a}} F_{a}(1 \mid B)=1$.

Observe that we allow for the regional distributions of preferences to overlap, while assuming that, whatever the government's type considered, the fraction of people with preferences to the left of this location is at least as large in region $A$ than in region $B$ (condition (i) above). Condition (ii) assumes that (regional and national) median types are unique, and that the nationwide median voter, $t^{m}$, is closer to region $A^{\prime}$ 's median voter, $t^{A}$, than to his counterpart in region $B, t^{B}$. Finally, condition (iii) shows what we mean by cultural distinctiveness: increasing $a$ pushes the regional preference distributions apart, with the limit case in (iv) of a totally polarized society. Observe that an individual of type $t^{m}$ always exists in region $A$, and may exist in region $B$ provided that the two regional distributions overlap sufficiently. 
The financial cost of implementing a government is independent of its type and is given by $g .{ }^{4}$ Government is a pure public good, so that $g$ is independent of the size of the jurisdiction. We further assume that this cost is equally shared among all citizens under the government's jurisdiction. The preferences of an individual located at $t$ are given by

$$
c-|x-t|,
$$

where $x$ denotes the type of government and $c$ the agent's consumption. If the agent lives in a unified country, his consumption level $c=c^{u}$ is given by

$$
c^{u} \equiv y-g
$$

If secession occurs, his utility depends of the region $R \in\{A, B\}$ he lives in, with $x=x_{R}$ the type of public good provided in region $R$ and the consumption levels $c=c_{R}^{S}$ given by

$$
c_{A}^{S} \equiv y-\frac{g}{1-\lambda} \text { and } c_{B}^{S} \equiv y-\frac{g}{\lambda} .
$$

We denote the economic loss for citizens in region $R$ that occurs with secession as $\Delta c_{R} \equiv c^{u}-c_{R}^{s}>0$, for each $R \in\{A, B\}$.

Events unfold as follows:

Stage 1. Citizens in the whole country choose by majority voting the type of the national government, $x \in[0,1]$.

Stage 2. A vote is taking place among region $B$ 's citizens to determine whether they want to secede or not. If a majority of region $B$ 's citizens favor secession, then a secession attempt occurs. Otherwise, the country remains united with a government's type of $x$, and the citizens receive their final payoff.

Stage 3. If a secession was attempted in Stage 2, region $A$ chooses (through majority voting) whether to fight to prevent the breaking up of the country or not.

Stage 4. If a majority of region $A$ 's citizens vote to fight the secession attempt by region $B$, this secession attempt is successful with probability $\pi \in[0,1]$ and the citizens in both regions $R$ incur a per capita monetary cost of conflict $\kappa_{R}>0$, $0<\kappa_{A} \leq \kappa_{B}$, whether secession is successful or not. ${ }^{5}$ If a majority of region $A$ 's

\footnotetext{
${ }^{4}$ We assume that this cost - a proxy for the size of government - is exogenous. See De Donder et al. (2012) for the joint political determination of the size and type of government.

${ }^{5}$ This cost can be either a financial cost incurred during the secession attempt or its repression (monetary value of assets destroyed, opportunity cost of resources invested,...) or a monetary measure of the intrinsic readiness of the region to either secede (for $B$ ) or repress secesssion (for $A$ ), like the ability to bear social unrest linked to demonstrations, civil war, or the heightened hate from members of the other group. The assumption that the per capita cost is larger for the citizens residing in the seceding region is very reasonable, if only because most if not all secession conflicts occur in the seceding region, where most of the physical damage takes place.
} 
citizens prefer not to resist, separation occurs with probability one without any conflict cost.

If the secession attempt is successful (irrespective of the decision by region $A$ to resist the attempt or not), a vote takes place in each region to determine the government's type in this region. If the secession attempt has been successfully repressed, the country remains united and a new vote takes place to choose the national government's type, but this time with no ensuing threat of secession. ${ }^{6}$

Finally, we will make use of the following tie-breaking assumption: Each citizen, when indifferent between an alternative leading to continued unity and an alternative leading to a secession crisis, always votes for the former in a pairwise comparison.

We now solve this model for the equilibrium institutional arrangement (unified country or secession) and policies.

\section{Equilibrium Policy and Risk of Secession}

As is usual, we solve the model backward, starting with the decisions taken in the last stages. If the secession attempt is successful, a vote takes place in both regions to determine the regional government's type. Preferences being single-peaked in $x$, a Condorcet winner exists (i.e., an option that is favored by a majority of voters to any other feasible option) and is given by the median most-preferred type in the region, $t^{R}, R \in\{A, B\}$. In the case secession is attempted but fails, the national vote over the unique government's type results in the national median type, $t^{m}$, being selected as the unique Condorcet winner.

Moving up the sequence of events, we now study the voting decision in region $A$ whether to fight a secession threat by region $B$ (stage 3 ). In the case where region $A$ does not fight, secession happens for sure and this region's equilibrium government's type is $t^{A}$. If region $A$ chooses to fight, everyone in $A$ supports a secession cost $\kappa_{A}$ and faces a lottery between policy $t^{A}$ in a smaller country and policy $t^{m}$ in the unified country. A citizen located at $t$ in region $A$ then prefers to repress a secession attempt by region $B$ if and only if

$$
\pi\left[c_{A}^{s}-\left|t^{A}-t\right|\right]+(1-\pi)\left[c^{u}-\left|t^{m}-t\right|\right]-\kappa_{A} \geq c_{A}^{s}-\left|t^{A}-t\right| .
$$

This condition is independent of the value of $x$ chosen in the first stage, since this policy is not on the table anymore once this decision node has been reached. For all agents located between $t^{A}$ and $t^{m}$, the incentive to oppose secession increases with

\footnotetext{
${ }^{6}$ This assumption is made to simplify the algebra. Our results hold through qualitatively provided that the secession threat is less prevalent than at stage 1 , so that region $A$ citizens are less willing to accommodate the preference of the minority region.
} 
the individual's location, as this moves the individual closer to the government's type chosen nationally, $t^{m}$, and away from the type chosen regionally, $t^{A}$. The incentive to oppose secession is minimum (and identical) for all agents located to the left of $t^{A}$, because the (negative) utility difference between national and regional government's type is minimum among region $A$ 's inhabitants, and is the same for all $t \leq t^{A}$. Likewise, the incentive to oppose secession is maximum (and identical) for all agents located to the right of $t^{m}$, because the (positive) utility difference between national and regional government's type is maximum among region $A$ 's inhabitants, and is the same for all $t \geq t^{m}$. This means that a majority of region $A$ 's citizens vote in favor of fighting region $B$ 's secession attempt if and only if the median regional type $t^{A}$ opposes secession, which is the case where

(F) $\kappa_{A} \leq(1-\pi)\left(\Delta c_{A}-\left(t^{m}-t^{A}\right)\right)$.

Observe that, since all agents with $t \leq t^{A}$ have the same preference regarding the attitude towards region $B$ 's secession attempt, condition $(\mathrm{F})$ actually ensures that all agents in region $A$ oppose the secession attempt by $B$. Region $A$ 's citizens are more likely to fight any attempt at secession by region $B$ (meaning that assumption $(\mathrm{F})$ is easier to satisfy) if the cost of fighting, $\kappa_{A}$, is low, if fighting has a high probability to scuttle the secession attempt ( $\pi$ low), if secession means forgoing a large part of the returns to scale associated with a single country $\left(\Delta c_{A}\right.$ large, because $g$ or $\lambda$ are large) and if the regional median likes the national policy $\left(\left(t^{m}-t^{A}\right)\right.$ small $)$.

As we are interested in the choice between accommodation of the minority preferences (stage 1) and repression, cases in which the majority region is prepared to repress secession attempts are our primary interest; so we assume in the remainder of the paper that $(\mathrm{F})$ holds. $^{7}$ It is readily checked, however, that all our theoretical results can be adapted to the case of peaceful secession by setting $\pi=1$ and $\kappa_{A}=\kappa_{B}=0$ in what follows.

We then move backward to stage 2 and study the secession attempt decision by region $B$. In case region $B$ does not attempt to secede, a national government of type $x$ is implemented. If it attempts to secede, region $B$ 's citizens anticipate that region $A$ will fight this attempt and that they will suffer a secession cost $\kappa_{B}$, resulting in the following lottery: enjoying the returns to scale of a large country with a government's type $t^{m}$, or living in a smaller jurisdiction with a government's type of $t^{B}$. A citizen $t$ in region $B$ prefers her region attempting secession if and only if

$$
\pi\left[c_{B}^{s}-\left|t^{B}-t\right|\right]+(1-\pi)\left[c^{u}-\left|t^{m}-t\right|\right]-\kappa_{B} \geq c^{u}-|x-t| .
$$

\footnotetext{
${ }^{7}$ The case where $(\mathrm{F})$ is not satisfied corresponds to peaceful secessions/separations, which seem empirically to be much less prevalent than repressed secession attempts (Walter, 2009).
} 
Incentives to secede increase the closer a region $B$ 's citizen is to $t^{B}$ and the further away she is from $x$, and are then maximum for citizens $t \geq t^{B} .{ }^{8}$ We then have that a majority in region $B$ favours secession if and only if

$$
x \leq \bar{x} \equiv \pi\left(t^{B}-\Delta c_{B}\right)+(1-\pi) t^{m}-\kappa_{B}<t^{B},
$$

where the threshold $\bar{x}$ denotes the minimum value of the national government's type such that a majority in region $B$ does not attempt to secede (anticipating that region $A$ will fight this secession attempt). This threshold value of $x$ is then a measure of region $B$ 's willingness to secede. Intuitively, this willingness (i) decreases with the cost to attempt secession, $\kappa_{B}$, (ii) increases when the median voter in region $B$, $t^{B}$, becomes more extreme or when the policy cost of a botched secession attempt decreases because $t^{m}$ increases, and (iv) decreases when the loss of the returns to scale associated with secession, $\Delta c_{B}$, becomes larger.

We define the secession set $\mathcal{S}$ as the set of policies such that region $B$ attempts to secede when $x$ is chosen in the first stage. ${ }^{9}$ Moving to the first stage choice of $x$, we assume that the secession threat by region $B$ is binding -i.e., that the majority chosen policy in the absence of a secession threat, $t^{m}$, belongs to the secession set:

A1: $\quad t^{m} \in \mathcal{S}\left(\Leftrightarrow t^{m}<\bar{x}\right)$.

If this assumption were not satisfied, the country would always remain united with the government's type located at $t^{m}$.

We can write the first stage policy preferences of a citizen $t$ living in region $R$ as follows

$$
v_{R}(x, t) \equiv \begin{cases}\pi\left[c_{R}^{s}-\left|t^{R}-t\right|\right]+(1-\pi)\left[c^{u}-\left|t^{m}-t\right|\right]-\kappa_{R} & \text { if } x \in \mathcal{S}, \\ c^{u}-|x-t| & \text { otherwise. }\end{cases}
$$

Observe that $v_{R}(x, t)$ does not depend upon $x$ provided that $x \in \mathcal{S}$, since in that case the minority region attempts to secede so that the implemented policy is either $t^{R}$ (if secession works out) or $t^{m}$ (if the attempt fails).

We prove the following lemma in the Appendix.

\footnotetext{
${ }^{8}$ We assume for the moment that $x<t^{B}$-i.e., that the national choice is never to the right of region $B$ 's median location. We come back to this assumption in the next footnote.

${ }^{9}$ Coming back to the previous footnote, there exists a value of $x$, which we denote by $\hat{x}$, such that $x>\hat{x}>t^{B}$ induces a majority of region $B$ to secede. Formally, $\mathcal{S} \equiv\{x \in[0,1]: x<\bar{x}$ or $x>\hat{x}\}$. This corresponds to the pathological case where the national policy $x$ is so extreme that the least extreme members of region $B$ prefer to secede in order to implement the less extreme policy $t^{B}$ rather than $x$. Allowing for this possibility does not change our results but treating it explicitly would increase the length of the paper without adding any intuition, so we concentrate on the cases where $x<\hat{x}$ in the remainder of the paper.
} 
Lemma 1. A Condorcet winner always exists when voting on $x$ in stage 1.

(i) If $v_{A}\left(\bar{x}, t^{m}\right) \geq v_{A}\left(x, t^{m}\right)$ for all $x \in \mathcal{S}$, then $\bar{x}$ is the unique Condorcet winner;

(ii) otherwise, either the set of Condorcet winners coincides with $\mathcal{S}$ or $\bar{x}$ is the unique Condorcet winner. In particular, there exists $a_{0} \in[\underline{a}, \bar{a}]$ such that the set of Condorcet winners coincides with $\mathcal{S}$ whenever $a \geq a_{0}$.

An immediate consequence of Lemma 1 is that a sufficient (although not necessary) condition for the (national) median citizen $t^{m}$ in region $A$ to be decisive (in the sense that a majority-winning alternative must maximize her utility) is that cultural distinctiveness is sufficiently large. Figure 1 depicts her preferences in two different cases. The dotted line represents her utility as a function of $x$ when the country remains united (second line in (2)) while the horizontal line represents her utility level when region $B$ attempts to secede (the first line in (2), which is independent of $x$ ). The bold line represents her utility as a function of $x$ when region $B$ 's secession decision is anticipated. The left panel corresponds to case (i) in the statement of Lemma 1, and the right panel to case (ii).

[Insert Figure 1 around here]

In the first case, $\bar{x}$ beats all alternatives outside of $\mathcal{S}$ (i.e., such that no secession is attempted) with the support of citizens located to the left of $\bar{x}$ (who form a majority thanks to $\mathrm{A} 1$ ), and beats all alternatives in $\mathcal{S}$ with the support of citizens located to the right of the median $t^{m}$. In the second case, any alternative in $\mathcal{S}$ beats any alternative not in $\mathcal{S}$ with the support of region $A$ 's citizens located to the left of $t^{m}$. Observe that this need not be the case for region $B$ 's citizens of similar location if the utility they obtain in $\mathcal{S}$ is lower than for a region $A$ 's citizen of identical location, which may be the case since region $B$ is smaller than region $A$, and since the secession crisis cost $\kappa_{R}$ is larger in region $B$ than in $A$. We show in the proof of Lemma 1 that a sufficiently large cultural distinctiveness between regions results in a (national) majority of people, all located in region $A$, preferring any alternative in $\mathcal{S}$ to any alternative not in $\mathcal{S}$. Finally, if the regional preference distributions do not overlap, than citizens of type $t^{m}$ are all located in region $A$, and are always decisive when voting on $x$.

Observe that, if the national median voter in region $A$ is not decisive, then secession is never an equilibrium of this model. In order to focus on the interesting and empirically relevant situations, we assume from now on that secession may occur at equilibrium-i.e., that type $t^{m}$ in region $A$ is decisive when voting on $x$. As explained above, a sufficient condition for this is that ${ }^{10}$

\footnotetext{
${ }^{10}$ Although it is possible to find overlapping regional preference distributions such that type $t^{m}$ in $A$ is not decisive, these distributions (available upon request from the authors) actually look very cooked up.
} 
A2: $a \geq a_{0}$.

An immediate consequence of this lemma is that unity is maintained at equilibrium (in which case $\bar{x}$ is enacted) if and only if $t^{m}$ prefers unity under $\bar{x}$ to a secession crisis:

$$
c^{u}-\left|\bar{x}-t^{m}\right| \geq \pi\left[c_{A}^{s}-\left|t^{A}-t^{m}\right|\right]+(1-\pi) c^{u}-\kappa_{A},
$$

or, equivalently,

$$
\bar{x} \leq \bar{y} \equiv \pi \Delta c_{A}+(1+\pi) t^{m}-\pi t^{A}+\kappa_{A} .
$$

The above expression captures nicely the two different sets of incentives in our model: $\bar{x}$ summarizes the incentives to secede of the minority, while $\bar{y}$ measures the willingness of the national decisive voter to accommodate region $B$ 's preferences (since $\bar{y}$ is the maximum value of $x$ that this voter is willing to implement in order to prevent region $B$ from attempting secession). The equilibrium institutional arrangement and government's type depend upon the comparison of these two thresholds, as summarized by

Proposition 1. A secession attempt is avoided at equilibrium if and only if

$$
\pi\left(t^{B}-\Delta c_{B}\right)-\kappa_{B} \leq \pi\left(\Delta c_{A}-t^{A}\right)+2 \pi t^{m}+\kappa^{A} .
$$

If this condition is satisfied, the implemented government's type is $\bar{x}$ for the whole unified country. If it is not, secession is attempted by region $B$ and the equilibrium policy corresponds to $t^{m}$ for the whole country with probability $1-\pi$ (failed attempt), and to $t^{R}$ in region $R$ with probability $\pi$ (successful attempt).

We now turn to the comparative static analysis of the equilibrium.

\section{Comparative Static Analysis of the Equilibrium}

Proposition 1 describes the conditions under which no secession attempt is made, because the decisive national median is ready to accommodate the minority while simultaneously region $B$ can be convinced not to secede. The ease with which secession can be prevented can be represented by $\delta \equiv \bar{y}-\bar{x}$, which measures the length of the range of policies that (i) do not induce region $B$ to secede and (ii) are preferred by the decisive national voter to the expected outcome in case of a 
secession attempt. We then assume that the equilibrium secession risk is decreasing in $\delta .{ }^{11}$

We perform the comparative static analysis of the secession risk at equilibrium, with the objective of showing that focusing on the willingness to secede (as is done by the CCB approach) may be misleading. We then study how this risk is affected by changes in the size of the minority region, the probability that a secession attempt by the minority is successful, and the cultural heterogeneity in the country, since those are the three areas where our predictions differ. ${ }^{12}$

One channel through which these variables influence the risk of secession is the modification of the identity of the national and regional median voters, $t^{m}, t^{A}$ and $t^{B}$. In order to quantify these impacts, we need to resort to specific functional forms for the distribution functions. We do this in a way that allows us to distinguish explicitly the heterogeneity of preferences between and within regions.

We assume that $F_{a}(\cdot \mid A)$ and $F_{a}(\cdot \mid B)$ are of the form:

$$
\begin{aligned}
& F_{a}(t \mid A) \equiv \begin{cases}0 & \text { if } t \in\left[0,1-a-v_{A}\right), \\
\frac{t+a+v_{A}-1}{2 v_{A}} & \text { if } t \in\left[1-a-v_{A}, 1-a+v_{A}\right], \\
1 & \text { if } t \in\left(1-a+v_{A}, 1\right]\end{cases} \\
& F_{a}(t \mid B) \equiv \begin{cases}0 & \text { if } t \in\left[0, a-v_{B}\right), \\
\frac{t-a+v_{B}}{2 v_{B}} & \text { if } t \in\left[a-v_{B}, a+v_{B}\right], \\
1 & \text { if } t \in\left(a+v_{B}, 1\right]\end{cases}
\end{aligned}
$$

where $a>\underline{a}=1 / 2$, and $v_{R} \leq 1-a, R \in\{A, B\}$. In words, the regional preference distributions are assumed to be uniform, with the distribution in region $A$ (resp., $B$ ) distributed around $1-a$ (resp., $a$ ) with $v_{A}$ (resp., $v_{B}$ ) measuring the dispersion around the mean/median regional location (so that $t^{A}=1-a$ and $t^{B}=a$ ). Observe that we allow the two distributions to overlap, which is the case if $1-a+v_{A}>a-v_{B}$ -i.e., if the regional dispersions $v_{A}$ and $v_{B}$ are large enough and if the median preferences in each region are close enough from each other. The nationwide median voter is the value of $t^{m}$ that solves:

$$
\begin{cases}(1-\lambda) \frac{t^{m}+a+v_{A}-1}{v_{A}}+\lambda \frac{t^{m}-a+v_{B}}{v_{B}} \equiv 1 & \text { if } 2 a \leq \frac{\lambda}{1-\lambda} v_{A}+v_{B}+1 \\ (1-\lambda) \frac{t^{m}+a+v_{A}-1}{v_{A}} \equiv 1 & \text { otherwise. }\end{cases}
$$

\footnotetext{
${ }^{11}$ We can show (notes available upon request to the authors) that our setting in this paper is formally equivalent (under certain conditions) to another where there is uncertainty as to the cost of secession for region $B, \kappa_{B}$, and where the equilibrium probability that this region attempts to secede is an increasing function of $\delta$.

${ }^{12}$ It is easy to see that a larger weight put on economic (as opposed to cultural) factors, as measured by $g$, results in both a lower willingness to secede and a higher willingness to accommodate, thereby decreasing the equilibrium risk of secession. In other terms, our model and the CCB approach share the same predictions as to the impact of $g$.
} 
The first line above corresponds to the case where $t^{m}$ belongs to the overlapping regional preferences segment (it is easy to see that the condition under which it happens is stronger than the condition for overlap stated above). It is readily checked that $t^{m} \in(1-a, a)$, so that

$$
t^{m} \equiv \begin{cases}\frac{(1-\lambda) v_{B}+a\left[\lambda v_{A}-(1-\lambda) v_{B}\right]}{\lambda v_{A}+(1-\lambda) v_{B}} & \text { if } 2 a \leq \frac{\lambda}{1-\lambda} v_{A}+v_{B}+1 \\ \frac{1-\left(1-v_{A}\right) \lambda}{1-\lambda}-a & \text { otherwise. }\end{cases}
$$

We start by analyzing the impact of the size of the minority, $\lambda$.

\subsection{Relative size of the minority}

Increasing the relative size of the minority region, $\lambda$, has three impacts: it moves the identity of the national decisive voter to the right (i.e., closer to the median wish in region $B$ ) while it decreases (resp., increases) the economic cost of secession for region $B$ (resp., $A$ ). We obtain that

$$
\frac{d \bar{x}}{d \lambda}=(1-\pi) \frac{d t^{m}}{d \lambda}-\pi \frac{d \Delta c_{B}}{d \lambda}= \begin{cases}\frac{\pi g}{\lambda^{2}}-\frac{(1-\pi)(1-2 a) v_{A} v_{B}}{\left[\lambda v_{A}+(1-\lambda) v_{B}\right]^{2}}>0 & \text { if } 2 a \leq \frac{\lambda}{1-\lambda} v_{A}+v_{B}+1 \\ \frac{\pi g}{\lambda^{2}}+\frac{(1-\pi) v_{A}}{(1-\lambda)^{2}}>0 & \text { otherwise. }\end{cases}
$$

so that region $B$ becomes more willing to secede since a larger $\lambda$ decreases the policy cost of a failed secession attempt (since $t^{m}$ increases with $\lambda$ ) and decreases the economic cost of a successful secession attempt as well. We also have that

$\frac{d \bar{y}}{d \lambda}=(1+\pi) \frac{d t^{m}}{d \lambda}+\pi \frac{d \Delta c_{A}}{d \lambda}= \begin{cases}\frac{\pi g}{(1-\lambda)^{2}}-\frac{(1+\pi)(1-2 a) v_{A} v_{B}}{\left[\lambda v_{A}+(1-\lambda) v_{B}\right]^{2}}>0 & \text { if } 2 a \leq \frac{\lambda}{1-\lambda} v_{A}+v_{B}+1 \\ \frac{\pi g+(1+\pi) v_{A}}{(1-\lambda)^{2}}>0 & \text { otherwise. }\end{cases}$

Raising $\lambda$ increases the willingness of the national decisive voter to accommodate region $B$, because of two effects playing in the same direction: a larger $\lambda$ (i) increases the value of the decisive voter's type $t^{m}$, moving her closer to region $B$ 's preferences, and (ii) increases the economic cost of secession for $t^{m}$.

With both $\bar{x}$ and $\bar{y}$ increasing with $\lambda$, the net impact on $\delta$ is a priori ambiguous. Straightforward manipulations tell us that

$$
\begin{aligned}
\frac{d \delta}{d \lambda} & =\pi\left(\frac{d \Delta c_{A}}{d \lambda}+\frac{d \Delta c_{B}}{d \lambda}+2 \frac{d t^{m}}{d \lambda}\right) \\
& = \begin{cases}-\pi\left[\frac{(1-2 \lambda) g}{\lambda^{2}(1-\lambda)^{2}}+\frac{2(1-2 a) v_{A} v_{B}}{\left[\lambda v_{A}+(1-\lambda) v_{B}\right]^{2}}\right] & \text { if } 2 a \leq \frac{\lambda}{1-\lambda} v_{A}+v_{B}+1 \\
\pi\left[\frac{2 v_{A}}{(1-\lambda)^{2}}-\frac{(1-2 \lambda) g}{\lambda^{2}(1-\lambda)^{2}}\right] & \text { otherwise. }\end{cases}
\end{aligned}
$$

so that the equilibrium risk of secession increases if $\lambda$ is low enough and/or $g$ is large enough. When $\lambda$ is very small, the economic impact of secession on region 
$B$ 's inhabitants decreases very fast with $\lambda$, which results in a lower $\delta$ (and thus a larger risk of secession). On the opposite, when $\lambda$ is large, the main driver is the economic loss for region $A$ in case of a successful secession attempt (since the cost of government $g$ is to be shared by a smaller proportion $1-\lambda$ of nationals), so that the risk of secession decreases. A large enough value of $g$ is a necessary condition for an increase in the risk of secession (because it amplifies the variations in the economic costs of secession when $\lambda$ increases). We then obtain the following proposition.

Proposition 2. As the relative size of the minority region, $\lambda$, increases:

(i) both the willingness to accommodate of the national median voter and the willingness to secede of region $B$ increase;

(ii) the equilibrium policy when no secession is attempted becomes more accommodating of the minority;

(iii) the risk of a secessionist conflict at equilibrium increases if $\lambda$ is small and/or $g$ is large.

We now move to the impact of the probability that a secession attempt is successful, $\pi$.

\subsection{Probability that a secession attempt is successful}

Raising the probability that a secession attempt is successful intuitively results in an increase in the willingness of region $B$ to secede:

$$
\frac{d \bar{x}}{d \pi}=t^{B}-\Delta c_{B}-t^{m}>0
$$

by assumption A1. In words, $t^{B}-t^{m}$ represents the marginal policy gain for region $B$ 's decisive voter when a secession attempt becomes more successful, while $\Delta c_{B}$ represents the marginal economic loss. The value of $\bar{x}$ increases with $\pi$ if the marginal gain is larger than the marginal loss, which is what assumption A1 implies.

Likewise, an increase in $\pi$ induces the national median voter to be more willing to accommodate region $B$ 's preferences:

$$
\frac{d \bar{y}}{d \pi}=\Delta c_{A}-t^{A}+t^{m}>0 .
$$

The net impact on the risk of a secession attempt is then ambiguous:

$$
\begin{aligned}
\frac{d \delta}{d \pi} & =\Delta c_{A}+\Delta c_{B}-\left(t^{A}+t^{B}\right)+2 t^{m} \\
& = \begin{cases}\frac{\lambda^{2}+(1-\lambda)^{2}}{\lambda(1-\lambda)} g-\frac{(1-2 a)\left[\lambda v_{A}-(1-\lambda) v_{B}\right]}{\lambda v_{A}+(1-\lambda) v_{B}} & \text { if } 2 a \leq \frac{\lambda}{1-\lambda} v_{A}+v_{B}+1, \\
\frac{\lambda^{2}+(1-\lambda)^{2}}{\lambda(1-\lambda)} g-\frac{2(1-\lambda) a+\left(1-2 v_{A}\right) \lambda-1}{1-\lambda} & \text { otherwise. }\end{cases}
\end{aligned}
$$


In countries where the weight attached to economic losses, $g$, is large, and cultural distinctiveness, $a$, is low, raising the probability that a secession attempt is successful tends to reduce the risk of a secession attempt. The effect of the minority's relative size, $\lambda$, is ambiguous, for it has opposing effects. First, it increases the median voter's type, $t^{m}$, thereby reducing (resp. raising) the policy gain of secession (resp. of maintained unity) for the minority (resp. the median voter). Second, a change in $\lambda$ also affects the marginal economic losses of both regions: positively for region $A$, and negatively for region $B$.

We obtain the following proposition.

Proposition 3. As the probability that a secession attempt is successful, $\pi$, increases:

(i) both the willingness to accommodate of the national median voter and the willingness to secede of region $B$ increase;

(ii) the equilibrium policy when no secession is attempted becomes more accommodating of the minority; and

(iii) the risk of a secessionist conflict at equilibrium decreases if $g$ is large and a is low.

Taking into account both the willingness to accommodate and to secede does not mean that the impact on the secession risk is always less clear-cut than when focusing only on the willingness to secede, as we show in the next section where we look at the cultural heterogeneity in the country.

\subsection{Cultural distinctiveness}

We first consider the preference heterogeneity between regions, as measured by the parameter $a$. It turns out that the impact of cultural distinctiveness occurs through changes in the identity of the decisive voters: raising $a$ unambiguously decreases $t^{A}$ and increases $t^{B}$. It also decreases $t^{m}$, provided that

$$
\lambda v_{A}<(1-\lambda) v_{B}
$$

This condition is intuitive: a larger value of $a$ decreases $t^{m}$ provided that there are few people in region $B$ ( $\lambda$ small) and that the preferences of these individuals are very thinly distributed around their median ( $\nu_{B}$ large). We assume from now on that condition (5) is satisfied. Observe that it is always the case when the two regional distributions do not overlap.

The impact of increasing cultural distinctiveness on the willingness of the minor- 
ity to secede, as measured by $\bar{x}$, is given by

$$
\begin{aligned}
\frac{d \bar{x}}{d a} & =\pi \frac{d\left(t^{B}-t^{m}\right)}{d a}+\frac{d t^{m}}{d a} \\
& = \begin{cases}\pi+(1-\pi) \frac{\lambda v_{A}-(1-\lambda) v_{B}}{\lambda v_{A}+(1-\lambda) v_{B}} & \text { if } 2 a \leq \frac{\lambda}{1-\lambda} v_{A}+v_{B}+1, \\
2 \pi-1 & \text { otherwise. }\end{cases}
\end{aligned}
$$

On the one hand, raising $a$ increases the distance between $t^{B}$ and $t^{m}$, which makes secession more appealing to region $B$ in case of a successful attempt. On the other hand, it decreases $t^{m}$, which makes secession less appealing in case the attempt is thwarted. In other words, increasing $a$ raises the stakes associated to a secession attempt by region $B$. The sign of the net impact of a on $\bar{x}$ is then ambiguous and depends upon the success probability $\pi$ : if it is low enough, the latter effect is larger than the former and region $B$ becomes less willing to secede, driving a decrease in $\bar{x}$. Keeping in mind that $\bar{x}$ corresponds to the implemented policy in case secession is prevented (i.e., when $\delta \geq 0$ ), we then obtain that more cultural distinctiveness between regions may lead to either a decrease or an increase in the equilibrium policy, depending upon the success probability $\pi$.

The impact of a larger cultural distinctiveness on the willingness of the national decisive voter to accommodate secessionist trends, as measured by $\bar{y}$, is given by

$$
\frac{d \bar{y}}{d a}=\frac{d t^{m}}{d a}+\pi \frac{d\left(t^{m}-t^{A}\right)}{d a}= \begin{cases}\pi+(1+\pi) \frac{\lambda v_{A}-(1-\lambda) v_{B}}{\lambda v_{A}+(1-\lambda) v_{B}} & \text { if } 2 a \leq \frac{\lambda}{1-\lambda} v_{A}+v_{B}+1 \\ -1 & \text { otherwise }\end{cases}
$$

Increasing $a$ has two effects of opposite signs on $\bar{y}$ : (i) the decrease in the identity of the decisive voter, the country median $t^{m}$, tends to decrease $\bar{y}$; (ii) the increase in the distance between $t^{m}$ and $t^{A}$ increases the decisive voter's utility cost of secession and thus the need to compromise to prevent secession, tending to increase $\bar{y}$. Observe that the second effect is present only if preferences overlap significantly (i.e., $t^{m}$ belongs to the interval where preferences overlap), so that $\bar{y}$ decreases unambiguously if preferences do not overlap. In case of overlapping preferences, the second effect is smaller than the first one provided that $\pi$ is small enough, in which case the overall impact of $a$ on $\bar{y}$ is negative: increased cultural distinctiveness unambiguously reduces the incentives of the national decisive voter to accommodate region $B$ and prevent secession.

We now look at the total effect of increasing $a$ on the equilibrium risk of secession, 
as measured by $\delta$ :

$$
\begin{aligned}
\frac{d \delta}{d a} & =\pi\left(-\frac{d\left(t^{A}+t^{B}\right)}{d a}+2 \frac{d t^{m}}{d a}\right) \\
& = \begin{cases}2 \pi \frac{\lambda v_{A}-(1-\lambda) v_{B}}{\lambda v_{A}+(1-\lambda) v_{B}}<0 & \text { if } 2 a \leq \frac{\lambda}{1-\lambda} v_{A}+v_{B}+1, \\
-2 \pi<0 & \text { otherwise. }\end{cases}
\end{aligned}
$$

This net effect is unambiguously negative, showing that, even though the impact on both equilibrium policy when no secession is attempted and on region $B$ 's willingness to secede is ambiguous, increasing the cultural distinctiveness across regions results in a larger risk of secession.

We summarize those results in the following proposition:

Proposition 4. A larger cultural distinctiveness between countries increases the risk of a secessionist conflict at equilibrium. The impact of cultural distinctiveness on both the willingness to secede by region $B$ and to accommodate by region $A$ is ambiguous, although it is negative in both cases provided that the probability of a successful secession attempt, $\pi$, is low enough.

We now move to the impact of the preference heterogeneity inside regions, starting with Region $A$. The only impact of a larger heterogeneity in region $A, v_{A}$, is to increase the identity of the national decisive voter, $t^{m}$ (this is intuitive, since a larger heterogeneity increases the proportion of region $A$ 's inhabitants with a mostpreferred type larger than any $t>1-a$ ). This in turn increases the willingness of region $B$ to secede (since a failed secession attempt becomes less costly in policy terms):

$$
\frac{d \bar{x}}{d v_{A}}=(1-\pi) \frac{d t^{m}}{d v_{A}}= \begin{cases}-(1-\pi) \frac{(1-2 a) \lambda(1-\lambda) v_{B}}{\left[\lambda v_{A}+(1-\lambda) v_{B}\right]^{2}}>0 & \text { if } 2 a \leq \frac{\lambda}{1-\lambda} v_{A}+v_{B}+1 \\ \frac{(1-\pi) \lambda}{1-\lambda}>0 & \text { otherwise, }\end{cases}
$$

while it also increases the willingness of the majority to accommodate (because the decisive voter moves to the right):

$$
\frac{d \bar{y}}{d v_{A}}=(1+\pi) \frac{d t^{m}}{d v_{A}}= \begin{cases}-(1+\pi) \frac{(1-2 a) \lambda(1-\lambda) v_{B}}{\left[\lambda v_{A}+(1-\lambda) v_{B}\right]^{2}}>0 & \text { if } 2 a \leq \frac{\lambda}{1-\lambda} v_{A}+v_{B}+1 \\ \frac{(1+\pi) \lambda}{1-\lambda}>0 & \text { otherwise. }\end{cases}
$$

We obtain that the impact on the willingness to accommodate is larger than on the willingness to secede, so that the risk of a secession attempt decreases with heterogeneity in region $A$ :

$$
\frac{d \delta}{d v_{A}}=2 \pi \frac{d t^{m}}{d v_{A}}= \begin{cases}-2 \pi \frac{(1-2 a) \lambda(1-\lambda) v_{B}}{\left[\lambda v_{A}+(1-\lambda) v_{B}\right]^{2}}>0 & \text { if } 2 a \leq \frac{\lambda}{1-\lambda} v_{A}+v_{B}+1 \\ \frac{2 \pi \lambda}{1-\lambda}>0 & \text { otherwise. }\end{cases}
$$


It is easy to see that we obtain the opposite impacts in region $B$.

We summarize those results in the next proposition.

Proposition 5. Increasing the heterogeneity of preferences inside region A (resp., $B$ ) results in an increase (resp., decrease) in both the willingness to secede by the minority region and to accommodate by the majority, and in a smaller (resp., larger) equilibrium risk of a secession attempt.

\section{$5 \quad$ Empirical Discussion and Concluding Remarks}

The framework developed here is a highly abstract model of secession crises. In our view, it is also the simplest structure within which to analyze not only the decision by a minority to secede (on which the existing literature has focused), but also the decision by the majority whether to accommodate the minority in order to dissuade secession, or to fight or accept a secession attempt by the minority.

While the CCB approach concentrates on the willingness to secede by the minority, we confront it to the willingness to accommodate by the majority to obtain the secession risk at equilibrium. We have shown that our predictions differ in terms of the impact on this secession risk of three sets of variables: the minority region size, the exogenous probability that a secession attempt is successful, and the cultural heterogeneity in the country.

The next step consists in confronting our predictions to data and empirical evidence as to the factors which affect the probability that a secessionist conflict takes place. On the impact of relative size, the CCB analysis obtains that a larger size of the minority decreases its cost of secession and thus should result in a larger secession probability. Our analysis shows that a larger minority size increases both the willingness to accommodate and to secede, with an ambiguous impact on the resulting secession probability. The empirical evidence on this matters seems more in line with our prediction, with some papers finding a positive impact of relative size (Fearon and Laitin (1999)) while others (Saideman and Ayres (2000) and Sorens (2005)) find no significant effect.

As for the impact of the (exogenous) probability that a secession attempt is successful and using the CCB approach, a larger probability decreases the cost of secession for the minority, resulting in a larger risk of secession at equilibrium. In our model, a larger probability increases both the willingness to accommodate and to secede, with an ambiguous net impact on the risk of secession. Now, it is difficult to find a good proxy for this probability that a secession attempt is successful, but we can find in the empirical literature two elements that have a positive impact on this probability: the support of neighboring states, and the existence of a large diaspora from the same ethnic group as the minority tempted by secession. According to the CCB approach, they should then increase the risk of secession. This is not what is 
observed in the data. As for the impact of a large diaspora, Boyle and Englebert (2006) state that "there is still little large-scale evidence of this link, for only Collier and Hoeffler (2002) have found a positive effect of diasporas on separatism. Their measurement, however, was limited to populations living in the United States, based on the 2000 census, which is likely to be a biased estimate." As for the support of a neighboring state, the empirical evidence suggests either no effect (Fearon and Laitin 1999) or a negative one (Sorens 2005).

One important characteristic of our modelling is that it disentangles the impact of cultural diversity between regions from those stemming from the heterogeneity in preferences inside regions. In both dimensions, our predictions differ from those obtained with the CCB approach. A larger heterogeneity between regions has an ambiguous impact on the willingness to secede, but results in an unambiguously larger equilibrium risk of secession once the willingness to accommodate is also taken into account. As for the heterogeneity inside regions, the impact on the willingness to secede (positive if region $A$ becomes more diverse, negative if region $B$ is more heterogeneous) is swamped by the impact on the willingness to accommodate, so that the risk of secession decreases (resp., decreases) if the majority (resp., minority) region becomes more heterogenous. The empirical literature has tested the claim that "cultural pluralism within a country will increase the number of secessionist claims." (Boyle and Englebert, 2006, p.7). Unfortunately, this literature has not tried to disentangle the impacts of inter- and intra-regional cultural pluralism. In the light of our model, it is then no surprise that "the evidence is rather weak if not contrarian, however. Hale (2000) and Sorens (2005) find positive relationships between ethnic/linguistic distinctiveness and separatist propensity. Yet, Treisman (1997:231), Laitin (2001: 852) and Saideman and Ayres (2000) found no evidence that ethnic antipathies or attachments to ethnic identities are important determinants of separatism. Further, Fearon and Laitin (1999) and Collier and Hoeffler (2002) observed that social fractionalization actually reduced the likelihood of identity wars and rebellions - as it makes it less likely for a specific group to have a distinct and sufficiently large regional" (Boyle and Englebert, 2006, p.7).

Granted, this is at most tentative empirical evidence that our model's predictions, when they differ from those of the CCB approach, are more empirically relevant. Or, in other words, that our model improves upon the CCB approach precisely where the empirical evidence does not conform with their predictions. To go beyond this first impression, there is need not only for more empirical research on the risk of secession, but more importantly on how much majorities accommodate their unruly minorities, and of what determines whether a secession attempt is fought or peacefully accepted by the majority. 


\section{Appendix: Proof of Lemma 1}

(i) Suppose that $v_{A}\left(\bar{x}, t^{m}\right) \geq v_{A}\left(x, t^{m}\right)$ for all $x \in \mathcal{S}$. As the preferences of all citizens are single-peaked on $\mathcal{U} \equiv[0,1] \backslash \mathcal{S}$ - with a peak at $\bar{x}$ - for all $t \leq \bar{x}$ (with $\bar{x}>t^{m}$ by A1), $\bar{x}$ is majority-preferred to any other government type $x \in \mathcal{U}$ (Median Voter Theorem). To establish the result, it suffices to show that, for all $x \in \mathcal{S}, v_{A}\left(\bar{x}, t^{m}\right) \geq v_{A}\left(x, t^{m}\right)$ implies $v_{A}(\bar{x}, t) \geq v_{A}(x, t)$ for all $t>t^{m}$.

Consider first a citizen $t$ in region $A$. She prefers $\bar{x}$ to $x \in \mathcal{S}$ if and only if

$$
c^{u}-|\bar{x}-t| \geq \pi\left[c_{A}^{s}-\left|t^{A}-t\right|\right]+(1-\pi)\left[c^{u}-\left|t^{m}-t\right|\right]-\kappa_{A},
$$

or, if $t \geq t^{m}$, equivalently,

$$
t-|\bar{x}-t| \geq \pi\left(t^{A}-\Delta c_{A}\right)+(1-\pi) t^{m}-\kappa_{A} .
$$

Since the left-hand side of the above inequality is strictly increasing in $t$ if $t<\bar{x}$ and constant in $t$ if $t \geq \bar{x}$, all citizens $t>t^{m}$ in region $A$ strictly prefer $\bar{x}$ to $x \in \mathcal{S}$ whenever $t^{m}$ weakly prefers $\bar{x}$ to $x$.

By construction of $\bar{x}$, citizens $t \geq t^{B}$ in region $B$ are indifferent between $\bar{x}$ and $x \in \mathcal{S}$ (and therefore vote for $\bar{x}$ ). Citizens $t \leq t^{B}$ in region $B$ weakly prefer $\bar{x}$ to $x \in \mathcal{S}$ if and only if

$$
c^{u}-|\bar{x}-t| \geq \pi\left[c_{B}^{s}-\left|t^{B}-t\right|\right]+(1-\pi)\left[c^{u}-\left|t^{m}-t\right|\right]-\kappa_{B},
$$

where the relationship holds with equality for $t=t^{B}$ by definition of $\bar{x}$. The derivative of the left hand side with respect to $t$ is strictly lower than the derivative of the right hand side when $\bar{x} \leq t<t^{B}$, proving that these individuals in region $B$ strictly prefer $\bar{x}$ to $\in \mathcal{S}$. Finally, consider citizens $t<\bar{x}$ in region $B$. Condition (6) can be rewritten as

$$
\xi^{t} \equiv \pi\left[t^{B}+\Delta c_{B}\right]-(1-\pi) t^{m}-\bar{x}+2(1-\pi) t+\kappa_{B} \geq 0 .
$$

Moreover $v_{A}\left(\bar{x}, t^{m}\right) \geq v_{A}\left(x, t^{m}\right)$ implies

$$
\xi^{m} \equiv(1+\pi) t^{m}-\pi\left(t^{A}-\Delta c_{A}\right)-\bar{x}+\kappa_{A} \geq 0 .
$$

To complete case (i), it thus suffices to check that $\xi^{t} \geq \xi^{m}$ for all $t \in\left(t^{m}, \bar{x}\right)$ :

$$
\begin{aligned}
\xi^{t}-\xi^{m} & =2(1-\pi) t+\pi\left(t^{A}+t^{B}\right)-2 t^{m}+\pi\left(\Delta c_{B}-\Delta c_{A}\right)+\kappa_{B}-\kappa_{A} \\
& >2(1-\pi)\left(t-t^{m}\right)>0 .
\end{aligned}
$$

(The first inequality comes from the fact that $t^{m}$ is closer to $t^{A}$ than to $t^{B}$.)

(ii) Suppose now that $v_{A}\left(\bar{x}, t^{m}\right)<v_{A}\left(x, t^{m}\right)$ for some (and therefore all) $x \in \mathcal{S}$. We first establish that the set of Condorcet winners is either $\mathcal{S}$ or $\{\bar{x}\}$ (and is 
consequently nonempty). If the set of Condorcet winners does not coincide with $\mathcal{S}$, then there must exist a government type $x \in \mathcal{U}$ that beats all the elements of $\mathcal{S}$ in a pairwise majority vote (recall that citizens who are indifferent between separation and unity with government type $x$ are assumed to vote for $x$ ). We now claim that this implies that $\bar{x}$ beats all the elements of $\mathcal{S}$ in a pairwise majority vote.

If $x=\bar{x}$, the claim is trivial; so suppose that $x \neq \bar{x}$. We want to prove that citizens who prefer $x$ to secession (i.e., to any element of $\mathcal{S}$ ) must also prefer $\bar{x}$ to secession. This is obvious for citizens $t \geq \bar{x}$ in region $\mathrm{A}$ and citizens $t \geq t^{B}$ in region $\mathrm{B}$, for they always prefer $\bar{x}$ to secession. All citizens $t \leq(\bar{x}+x) / 2$ (in both regions) prefer $\bar{x}$ to $x$. As a consequence, they prefer $\bar{x}$ to secession $\mathcal{S}$ whenever they prefer $x$ to the elements of $\mathcal{S}$. Finally, consider a citizen $t \in\left((\bar{x}+x) / 2, t^{B}\right)$ in region $\mathrm{B}$ : As $t^{m}<\bar{x}<t<t^{B}$,

$$
\begin{aligned}
c^{u}-t+\bar{x} & \equiv c^{u}-t+\pi\left(t^{B}-\Delta c_{B}\right)+(1-\pi) t^{m}-\kappa_{B} \\
& =\pi\left(c_{B}^{s}-t^{B}+t\right)+(1-\pi)\left(c^{u}-t+t^{m}\right)-\kappa_{B}+2 \pi\left(t^{B}-t\right) \\
& >\pi\left(c_{B}^{s}-t^{B}+t\right)+(1-\pi)\left(c^{u}-t+t^{m}\right)-\kappa_{B}
\end{aligned}
$$

which implies that she prefers $\bar{x}$ to secession. This proves that all members of the majority preferring $x$ to secession also prefer $\bar{x}$ to secession. As $\bar{x}$ is majoritypreferred to all $y>\bar{x}$, it must be the unique Condorcet winner. This proves that the set of Condorcet winners is either $\mathcal{S}$ or $\{\bar{x}\}$.

We now establish that there exists $a_{0} \in(\underline{a}, \bar{a})$ such that the set of Condorcet winners coincides with $\mathcal{S}$ whenever $a \geq a_{0}$. To do so, we first show that, for any $x \in \mathcal{S}$ and any $x^{\prime} \in \mathcal{U}, v_{A}\left(x, t^{m}\right)>v_{A}\left(x^{\prime}, t^{m}\right)$ if and only if $v_{A}(x, t)>v_{A}\left(x^{\prime}, t\right)$ for all $t \leq t^{m}$ in region $\mathrm{A}$. Consider a region $A$ citizen with $t<t^{m}$ : she (strictly) prefers $x$ to $x^{\prime}$ if and only if

$$
c^{u}-\left|x^{\prime}-t\right|<\pi\left[c_{A}^{s}-\left|t^{A}-t\right|\right]+(1-\pi)\left[c^{u}-\left|t^{m}-t\right|\right]-\kappa_{A},
$$

or, equivalently,

$$
\pi\left[t+\left|t^{A}-t\right|\right]<x^{\prime}-\pi \Delta c_{A}-(1-\pi) t^{m}-\kappa_{A} .
$$

As the left-hand side of the above inequality is weakly increasing on $\left[0, t^{m}\right]$, this proves that all citizens $t \leq t^{m}$ in region A strictly prefer $x$ to $x^{\prime}$. As $v_{A}(x, t)-$ $v_{A}\left(x^{\prime}, t\right)$ is continuous in $t$, there exists $\gamma>0$ such that all region A's inhabitants in $\left[t^{m}, t^{m}+\gamma\right)$ also prefer $x$ to $x^{\prime}$. As $F_{a}\left(t^{m}+\gamma \mid A\right)$ is increasing in $a$ and

$$
(1-\lambda) \lim _{a \rightarrow \bar{a}} F_{a}\left(t^{m}+\gamma \mid A\right) \geq(1-\lambda) \lim _{a \rightarrow \bar{a}} F_{a}(0 \mid A)=1-\lambda>\frac{1}{2},
$$

there must exist $a_{0} \in(\underline{a}, \bar{a})$ such that the set of region A's citizens in $\left[0, t^{m}+\gamma\right)$ constitutes a majority of the population. This proves that any $x \in \mathcal{S}$ beats any $x^{\prime} \in \mathcal{U}$, thus completing the proof of the lemma. 


\section{References}

Alesina, A., Spolaore, E., 1997. On the Number and Size of Nations. Quarterly Journal of Economics 112, 1027-1056.

Boyle K., Englebert, P., 2006. The Primacy of Politics in Separatist Dynamics. Paper presented at the Annual Meeting of the International Studies Association, San Diego, March 2006.

Collier, P., Hoeffler, A., 2002. The Political Economy of Secession. Development Research Group, World Bank; Center for the Study of African Economies, $1-22$.

De Donder, Ph., Le Breton, M., Peluso, E., 2012. On the (Sequential) Majority Choice of Public Good Size and Location. Social Choice and Welfare. DOI $10.1007 / \mathrm{s} 00355-012-0656-4$

Drèze, J., Le Breton, M., Weber, S., 2007. Rawlsian Pricing of Access to Public Facilities: A Unidimensional Illustration. Journal of Economic Theory 136, 759-766.

Fearon, J. D., Laitin, D.D., 1999. Weak States, Rough Terrain, and Large-Scale Ethnic Violence. Paper presented at the 1999 Annual Meetings of the American Political Science Association, Atlanta, GA, September 1999.

Goyal, S., Staal, K., 2004. The political economy of regionalism. European Economic Review 48, 563-593.

Gurr, T. R., 2000. Peoples Versus States: Minorities at Risk in the New Century. Washington D.C.: U.S. Institute of Peace Press

Haimanko, O., Le Breton, M., Weber, S., 2005. Transfers in a Polarized Country: Bridging the Gap between Efficiency and Stability. Journal of Public Economics 89, 1277-1303.

Haimanko, O., Le Breton, M., Weber, S., 2007. The Stability Threshold and the Two Facets of Polarization. Economic Theory 30, 415-430.

Hale, H., 2000. The Parade of Sovereignties: Testing Theories of Secession in the Soviet Setting. British Journal of Political Science 30:31-56.

Laitin, D., 2001. Secessionist Rebellion in the Former Soviet Union. Comparative Political Studies, 34:8, 839-61. 
Le Breton, M., Weber, S., 2003. The Art of Making Everybody Happy: How to Prevent a Secession. IMF Staff Papers 50, 403-435.

Le Breton, M., Weber, S. 2004. Secession-Proof Cost Allocations and Stable Group Structures in Models of Horizontal Differentiation. In Group Formation in Economics: Networks, Clubs and Coalitions, Demange, G. and M. Wooders, eds., Cambridge University Press, 266-285.

Lustick, I.S., Miodownik, D., Eidelson, R.J., 2004. Secessionism in Multicultural States: Does Sharing Power Prevent or Encourage It? American Political Science Review 98, 209-229.

Ruta, M., 2005. Economic Theories of Political (Dis)Integration. Journal of Economic Surveys 19, 1-21.

Saideman, S., Ayres, W., 2000. Determining the Causes of Irredentism: Logit Analysis of Minorities at Risk Data from the 1980s and 1990s. The Journal of Politics 62:1126-44.

Sorens, J., 2005. The Cross-Sectional Determinants of Secessionism in Advanced Democracies. Comparative Political Studies 38, 304-26.

Spolaore, E., 2008. Civil Conflict and Secessions. Economics of Governance 9 (1), 45-63.

Spolaore, E., forthcoming. Federalism, Regional Redistribution, and Country Stability. In Studies in Fiscal Federalism and State-Local Finance, Wallace Oates series. Edward Elgar Publishing.

Treisman, D., 1997. Russia's 'Ethnic Revival' The Separatist Activism of Regional Leaders in a Postcommunist Order. World Politics 49:212-49.

Walter, B.F., 2009. Reputation and Civil War: Why Separatist Conflicts Are So Violent. Cambridge University Press 

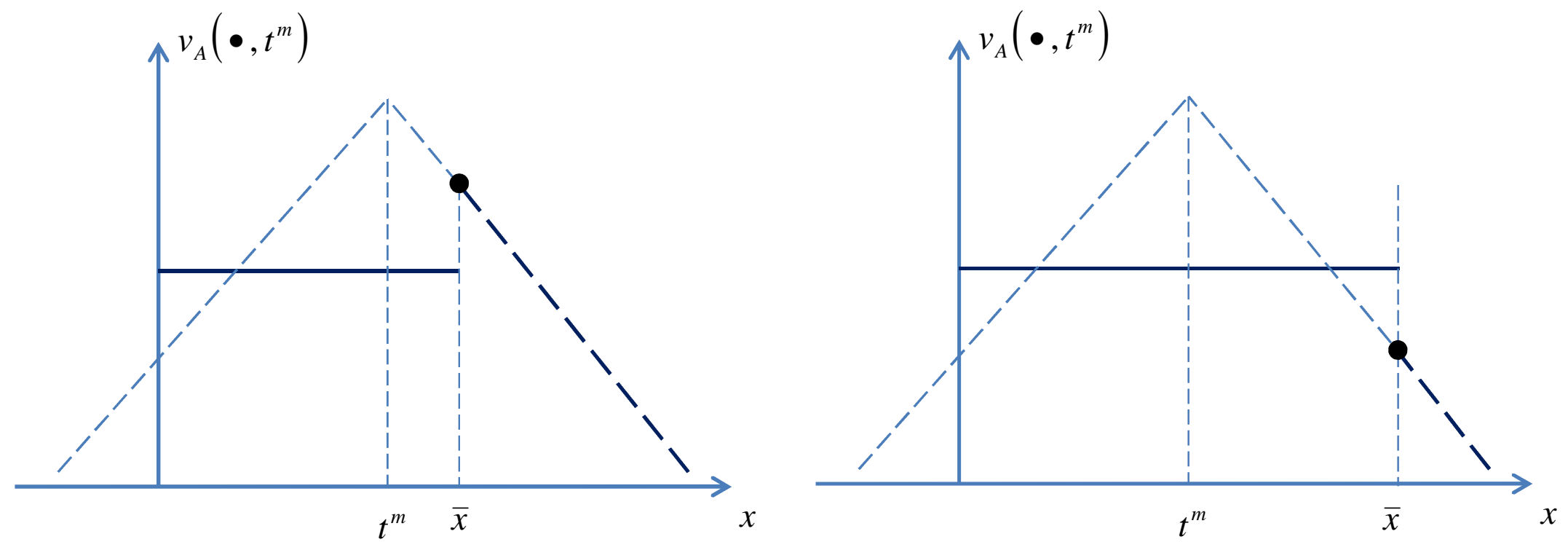

Figure 1: Policy preferences of the median citizen living in region $A$. 